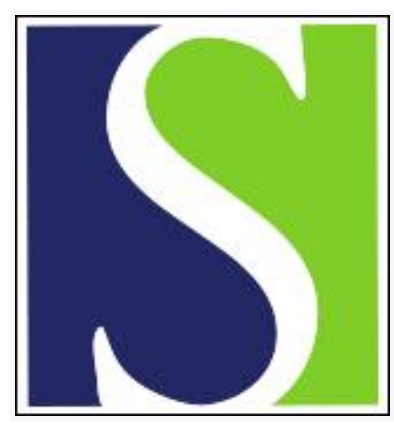

Scand J Work Environ Health 1998;24(1):3-7

https://doi.org/10.5271/sjweh.271

Issue date: Feb 1998

\title{
Environmental risk factors of breast cancer
}

by Welp EA, Weiderpass E, Boffetta P, Vainio H, Vasama-Neuvonen K, Petralia S, Partanen TJ

The following article refers to this text: 2001;27(3):161-213

Key terms: halogenated hydrocarbons; mutation; occupation; pesticide; postmenopausal women; solvent; xenoestrogen

This article in PubMed: www.ncbi.nlm.nih.gov/pubmed/9562394 


\title{
Environmental risk factors of breast cancer
}

\author{
by Esther A Welp, MSc, ${ }^{1}$ Elisabete Weiderpass, MD, ${ }^{2,3}$ Paolo Boffetta, MD, ${ }^{4}$ Harri Vainio, MD, ${ }^{4}$ \\ Kaisa Vasama-Neuvonen, MSc, ${ }^{2}$ Sandra Petralia, PhD, ${ }^{5}$ Timo J Partanen, PhD ${ }^{2}$
}

\begin{abstract}
Welp EA, Weiderpass E, Boffetta P, Vainio H, Vasama-Neuvonen K, Petralia S, Partanen TJ. Environmental risk factors of breast cancer. Scand J Work Environ Health 1998;24(1):3-7

Breast cancer is women's most ubiquitous cancer. The role of dietary factors is controversial, but there is limited evidence for such occupational risk factors as employment in the pharmaceutical industry and as a beautician. Ionizing radiation probably increases the risk. Exposure to chlorinated hydrocarbon pesticides, chlorinated solvents, and polychlorinated biphenyls may be risk factors, although the evidence is insufficient. Data on low-frequency electromagnetic fields are inconclusive. Tobacco smoking may be a risk factor, but the effect may depend on $\mathrm{N}$-acetyltransferase 2 genetic polymorphisms. There are yet unidentified determinants, probably environmental, that may act via estrogenic activity or through other mechanisms. The etiology may vary according to the joint estrogen and progesterone receptor status of the tumor. P53 mutation frequency varies considerably in breast cancer populations, which may reflect variation in exogenous exposures. Epidemiology research on breast cancer needs to consider subtypes of the disease, lifetime exposure assessment, host susceptibility, and adjustment for reproductive and menstrual history.
\end{abstract}

Key terms halogenated hydrocarbons, mutations, occupation, pesticides, postmenopausal women, solvents, xenoestrogens.

Breast cancer is women's most ubiquitous cancer in the majority of world populations, with over 910000 new cases estimated to occur worldwide annually (1). Some $75 \%$ of breast cancers are diagnosed among postmenopausal women, and the log of the risk increases linearly with the log of age until menopause. The breast cancer incidence, reported by cancer registries around the world, shows an over 10-fold variation across populations. The highest incidence rates (over 100 per 100 000) were observed among Caucasians living in Zimbabwe and among whites in San Francisco and Los Angeles in the United States. The lowest incidence rates (less than 10 per 100 000) were observed in Algeria (Setif), India (Barshi), Korea (Kangwha), and Thailand (Khon Kaen) (1).

Breast cancer incidence has increased throughout the world during the past 2 decades (2). In several populations this increase in incidence coincides with a decrease in mortality. Although the causes of these diverging trends are incom- pletely understood, a combination of earlier diagnosis -- due to increased awareness and more widespread mammographic screening — and the use of adjuvant therapy appears likely. The 5-year relative survival of breast cancer for those diagnosed under 65 years of age was $84 \%$ among Caucasians and $69 \%$ among Afro-Americans in the United States during 1986-1993 (SEER Cancer Statistics Review 1973-1994, National Cancer Institute Webside). In Europe, the 5-year survival rate in the 1980 s was about $70 \%$ (3).

The epidemiology of breast cancer has been investigated extensively, and recent reviews are available (4-7). Most of the risk factors established for breast cancer are linked to total lifetime exposure to bioavailable estrogens, and they are due to acquired mutations (8). Early menarche and late menopause increase the lifelong estrogen load and are recognized risk factors of breast cancer. Thus menopause at age 45 years or older carried a 2.5 -fold risk, compared with that of women

1 Department of Environmental Health, University of Washington, Seattle, Washington, United States of America.

2 Finnish Institute of Occupational Health, Helsinki, Finland.

3 Department of Medical Epidemiology, Karolinska Institute, Stockholm, Sweden.

4 International Agency for Research on Cancer, Lyon, France.

$5 \quad$ National Cancer Institute, Rockville, Maryland, United States of America.

Reprint requests to: Dr Elisabete Weiderpass, Department of Medical Epidemiology, PO Box 281, Karolinska Institute, S-171 77 Stockholm, Sweden. [e-mail: Elisabete.Weiderpass@MEP.KI.SE] 
with menopause before the age of 45 years, in data from the United States (9). Hormone replacement therapy represents an additional risk. A pooled analysis of 51 studies, based on data from 53865 women, in 21 countries, reported a risk of 1.35 [95\% confidence interval $(95 \%$ CI $) 1.21-1.49]$ for users of hormone replacement therapy for 5 years. The effect increases with duration of use and is reduced after 5 years of cessation of treatment. These results did not vary markedly with different hormonal types or doses (10). Oral contraceptives seem to represent a slight increase in risk shortly after the users' quit using them, but the excess disappears within 10 years (11). In the United States, it has been estimated that the population attributable risk is $30 \%$ for breast cancer among women giving birth for the first time at a later age and for women who have no children (9). A combined analysis of 6 dietary case-referent studies indicates an estimated $70 \%$ excess risk for women consuming over 4 alcoholic drinks a day (12), probably due to alterations of estrogen metabolism.

Postmenopausal obesity is a risk factor, probably due to estrogen formation in adipocites (13). The quantification of the role of diet in the development of the breast is still problematic and unclear. Since the quantity and distribution of adipose tissue may be a cofactor in the development of breast cancer, a link with fat intake has been proposed. However, in a pooled study of 4980 cases from 7 prospective cohorts, breast cancer risk was not associated with total fat, saturated fat, monounsaturated fat, polyunsaturated fat, animal fat, vegetable fat, or cholesterol intake (14). Early, intense exposure to ionizing radiation is a recognized risk factor. Risk ratios for women with intense radiation therapy or atomic bomb survivors range from 2 to 6 (15).

Inheritance probably accounts for less than $10 \%$ of all breast cancers. Host susceptibility genes BRCA1 and BRCA2 are frequently mutated in familial breast cancers in young women. These mutations are less frequent in postmenopausal breast cancer (16). For exposure to tobacco smoking there is little or no persuasive epidemiologic evidence of an association. Results of a recent study (17), however, suggest that slow acetylators who were heavy smokers 20 years before have a 4 -fold risk ( $95 \%$ CI 1.4-10.8) of postmenopausal breast cancer, while among fast acetylators heavy smoking seemed to be inversely related to risk [odds ratio (OR) 0.3 , $95 \% \mathrm{CI} 0.1-0.8]$. The acetylator status deals with $\mathrm{N}$-acetyltransferase 2 genetic polymorphism (17).

The risk for breast cancer follows a clear socioeconomic trend, with a steep gradient towards high risk in high social strata in at least 14 populations on 4 continents, with a singular possible exception of Switzerland (18). The trend may be indirectly linked, at least in part, to different cumulative doses of endogenous or exogenous estrogens and progestagens in different socioeconomic strata. Socioeconomic status, along with reproductive history, use of exogenous hormones, somatotype, and alcohol consumption may therefore represent confounders and effect modifiers in occupational and environmental studies of postmenopausal breast cancer. Much of the uncertainty concerning occupational and environmental determinants of breast cancer probably derives from simplistic models and incomplete control of confounding. The higher incidence among women in high socioeconomic strata may mask potentially work-induced excesses among women in lower strata who encounter chemical exposures at work more frequently. The attributable risk for breast cancer associated with high socioeconomic status has been estimated to be $19 \%$ (18).

It has also been proposed that the increase in incidence is primarily due to an increase of estrogen receptor-positive tumors. Patients with these tumors have better survival rates or respond relatively well to hormone therapy. An Australian study (19) failed to provide strong evidence for different causal pathways for estrogen-positive and estrogen-negative breast cancers. However, the etiology may be different according to the joint estrogen and progesterone receptor status of the tumor; this suggestion implies that there are distinct subtypes of breast cancer (20).

Hypotheses on exogenous causes of breast cancer have also been advanced. Thus breast cancer risk has been suggested to be jointly determined by exposure to exogenous carcinogens and breast tissue susceptibility, the latter being influenced by reproductive patterns (21). Various compounds that are widespread in the environment may bind to hormonal receptors, and they may have either estrogenic, antiestrogenic, androgenic, or antiandrogenic effects and thereby potentially influence the risk of breast cancer. Such compounds include chlorinated organic compounds such as dichlorodiphenyltrichloroethane (DDT), polychlorinated biphenyls (PCB), and polynuclear aromatic compounds such as benzo[a]pyrene and triazine herbicides.

Several halogenated pesticides that may act as xenoestrogens are persistently deposited in adipose tissue. Women occupationally or otherwise exposed to these agents might therefore experience an excess of breast cancer.

Reports linking biological organochlorine concentrations with the risk of breast cancer in women have been published and also recently reviewed (22). The main source of the organochlorines seems to have been residues in animal food products (eg, fat, fish, and milk derivates). Out of 4 small studies, $2(23-24)$ reported elevated risk associated with DDT or its primary metabolite, DDE, and breast cancer, while 2 (2526) did not. One larger study with stronger methods from New York (27) reported a positive association. A second, well-designed study (28), with higher exposure levels than in the former study, identified (weak and nonsignificant) positive exposure-response gradients for DDE in Caucasian and African American women, but not for DDT in Asian women residing in the San Francisco Bay area. A third European study (29) has shown a decreasing trend for adipose DDE concentration and breast cancer in postmenopausal women. In a further small study in Quebec (30), DDE concentrations in the adipose tissue of breast cancer patients were 3-fold those of referents, and the PCB concentrations were also signifi- 
cantly higher in the patients. In a recent Mexican case-referent study (31), the cases had an overall higher DDE serum concentration, but no elevation in risk was observed. However, particularly the older California data and the more recent European data are difficult to compare because the exposure ranges differ widely (figure 1). Comparability is also disturbed by different proportions of postmenopausal women in the 3 studies.

Finally, there is some evidence from occupational studies that 2,3,7,8-tetrachlorodibenzo-paradioxin (TCDD) or higher dioxins may be risk factors (32). The findings bear relevance also for occupational exposure, since chlorinated pesticides, banned in many countries, are still in use in others, and occupational exposures occur during application. For women who apply organochlorine pesticides in agriculture, especially in the tropics, the exposure levels are likely to be or to have been higher than for subjects in studies conducted in industrialized countries. Epidemiologic studies on women in agriculture may therefore be of interest. Detailed exposure assessment is however necessary since some organochlorine compounds, such as DDT or chlordecone, are estrogenic but others, such as TCDD and possibly lindane, are antioestrogenic, and some may have no estrogenic role (22). The effect of mixed exposure to different organochlorines is largely unknown. In this context it is important to stratify the analysis by estrogen and progesterone receptor status since estrogenic compounds may be a greater risk for estrogen receptor-positive $(E R+)$ tumors than for estrogen receptor-negative (ER-) tumors.

Exposures to these chemicals, and also to halogenated hydrocarbon solvents such as trichloroethylene or tetrachloroethylene, are of particular interest because they are retained in adipose tissue. There is little epidemiologic evidence for the breast carcinogenicity of these solvents, however. Reported risk ratios range from 0.1 to $1.1(33-36)$ for employees in dry cleaning facilities, where exposures to both chlorinated and nonchlorinated hydrocarbon solvents have been taking place among a large number of women. A recent study (37) reported a relative risk of 0.9 for women occupationally exposed to trichloroethylene, tetrachloroethylene, and 1,1,1trichloroethane.

There are probably carcinogenic pathways independent of the estrogenic properties of the xenobiotic agents $(21,38)$. Irrespective of the mechanism, since the established risk factors for breast cancer account only for about one-third of the breast cancer cases, there seem to be yet unidentified determinants, some possibly being environmental.

A comprehensive review of occupational risk factors for female breast cancer (6) showed limited evidence for an association with employment in the pharmaceutical industry and among cosmetologists and beauticians. Ionizing radiation, whether occupational (eg, radiologists, nurses, and X-ray technicians), diagnostic or therapeutic, is probably associated with an increase in breast cancer risk. There is some evidence of low-frequency electromagnetic fields being associated with

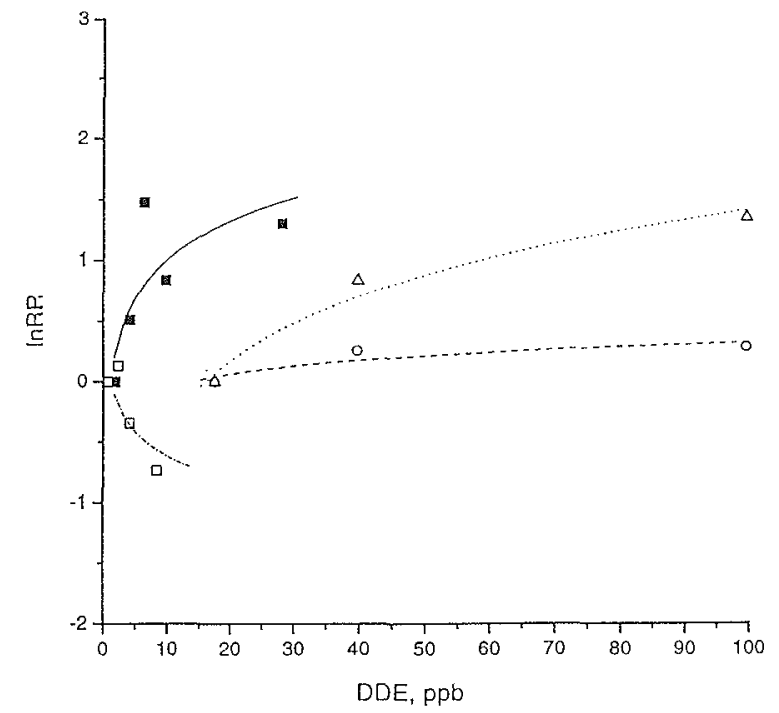

Figure 1. Data from 3 studies, by Wolff et al in New York (27), by Krieger et al in the San Francisco Bay area in California (28) and by Van't Veer et al in Europe (29) on the DDE [1,1-dichloro-2,2-bis(4chlorophenyl)] concentration in blood and the risk of breast cancer. Log function was fitted to each. The European concentrations were conjectured from fatty tissue concentrations. Note the low exposure range of the European data particularly contrasted with high earlier California concentrations. ( $=$ women in the Wolff study, $\Delta=$ African American women in the Krieger et al study, $O=$ all the women in the Krieger et al study, $\square=$ European women in the Van't Veer et al study, InRR = natural log of the risk ratio)

breast cancer risk (6), but the causality of this potential link is disputable. The putative mechanism is that $60-\mathrm{Hz}$ electric fields (and uninterrupted light) decrease pineal melatonin, which induces a constant production of estrogen and prolactin (39). There was little support for increased risks among textile workers, dry cleaning workers, and nuclear industry workers. Data on leisure-time or work-related physical activity and postmenopausal breast cancer suggest a protective effect (40). Teachers showed the highest breast cancer mortality experience for both whites and blacks in 23 American states during the period 1979-1987 (41). In at least 2 out of 3 recent register linkage studies, significant excesses for breast cancer risk have been shown for women working as bookbinders, nurses, teachers, social workers, or cashiers (42-44). Airline cabin attendants have been reported to be at increased risk of breast cancer, which may be associated with exposure to ionizing radiation during flights (45).

A recent study (46) linked job title in the death certificate with subsequent cancer mortality in 24 American states and adjusted breast cancer rates for socioeconomic status. Suggestive associations were reported for breast cancer mortality and exposure to styrene, methylene chloride, carbon tetrachloride, formaldehyde, and several metals and metal oxides and acid mists, as assessed with the use of a job-exposure matrix in the translation of job titles into exposure indicators.

The foregoing examples indicate that environmental and occupational factors may play a role in the development of 
women's breast cancer, but the identification of these factors is not straightforward. We advance the following proposals for the targeting of etiologic studies of postmenopausal breast cancer: (i) environmental and occupational risk factors of postmenopausal breast cancer are for the most part unknown but may be more important than currently considered, (ii) careful individual lifetime exposure assessment is necessary, (iii) pre- and postmenopausal breast cancers should be treated as separate entities because of potentially different etiologies, (iv) adjustment for reproductive and menstrual histories and other risk factors is needed, since occupation may be related to parity and age at first birth, with women in occupations which require more education having fewer children and having their first birth at later ages than women with less education, (v) subtypes of breast cancer may have different etiologies according to estrogen and progesterone receptor status and might therefore be considered separate end points in epidemiologic studies, (vi) both early and late stages of carcinogenesis may be involved in environmentally influenced breast cancer and various lagging schemes should therefore be allowed for in assessments of exposures, and (vii) in general, there is a poor appreciation of factors that control individual genetic susceptibility to external factors.

\section{Acknowledgments}

This study was funded by the Finnish Work Environment Fund for a study entitled "Women's Occupational Cancer". We thank Professor Hans-Olov Adami and Dr Aaron Blair for their critical review of the manuscript.

\section{References}

1. Parkin DM, Whelan S, Ferlay J, Reymond L, Young J. Cancer Incidence in five continents; vol VII. Lyon: International Agency for Research on Cancer (IARC), 1997. IARC scientific publications, no 143.

2. Coleman MP, Esteve J, Damiecki P, Arslan A, Renard H. Trends in cancer incidence and mortality. Lyon: International Agency for Research on Cancer (IARC), 1993. IARC scientific publications, no 121.

3. Berrino F, Sant M, Verdecchia A, Capocaccia R, Hakulinen T, Esteve J. Survival of cancer patients in Europé: the EUROCARE study. Lyon: International Agency for Research on Cancer (IARC), 1995. IARC scientific publications, no 135 .

4. Kuller LH. The etiology of breast cancer - from epidemiology to prevention. Public Health Rev 1995;23:157-213.

5. Kelsey JL, Gammon MD. Epidemiology of breast cancer. Epidemiol Rev 1990;12:228-40.

6. Goldberg M, Labreche M. Occupational risk factors for female breast cancer. Occup Environ Med 1996;53:145 - 56.

7. Henderson BE, Pike MC, Bernstein L, Ross RK. Breast cancer. In: Schottenfeld D, Fraumeni JF Jr, editors. Cancer epidemiology and prevention. New York (NY): Oxford University Press, 1996.

8. Davis DL, Bradlow HL, Wolff M, Woodruff T, Hoel DG, AntonCulver H. Medical hypothesis: xenoestrogens as preventable causes of breast cancer. Environ Health Perspect 1993;101:372 7 .

9. Madigan MP, Ziegler RG, Benichou J, Byrne C, Hoover RN. Proportion of breast cancer cases in the United States explained by wellestablished risk factors. JNCI 1995;87:1681 -5 .

10. Collaborative Group on Hormonal Factors in Breast Cancer. Breast cancer and hormone replacement therapy: collaborative reanalysis of data from 51 epidemiological studies of 52705 women with breast cancer and 108411 women without breast cancer. Lancet 1997;350:1047-59.

11. Collaborative Group of Hormonal factors in Breast Cancer. Breast cancer and hormonal contraceptives: collaborative reanalysis of individual data on 53297 women with breast cancer and 100239 women without breast cancer from 54 epidemiological studies. Lancet 1996:347:1713-27.

12. Howe G, Rohan T, Decarli A, Iscovich J, Kaldor J, Katsouyanni K, et al. The association between alcohol and breast cancer risk: evidence from the combined analysis of six dietary case-control studies. Int $\mathbf{J}$ Cancer 1991:47:707-10.

13. Hulka BS, Stark AT. Breast cancer; cause and prevention. Lancet 1995;346:883-7.

14. Hunter DJ, Spiegelman D, Adami H-O, Beeson L, Van den Brandt PA, Folmsom AR, et al. Cohort studies of fat intake and the risk of breast cancer — a pooled analysis. NEngI J Med 1996;334:356-61.

15. Wolff MS, Weston A. Breast cancer risk and environmental exposures. Environ Health Perspect 1997;105 suppl 4:891 —6.

16. Greene MH. Genetics of breast cancer. Mayo Clin Proc 1997;72:54 65.

17. Ambrosone CB, Freudenheim $\mathrm{L}$, Graham S, Marshall JR, Vena JE, Brasure JR, et al. Cigarette smoking, $\mathrm{N}$-acetyltransferase 2 genetic polymorphisms, and breast cancer risk. JAMA 1996;276:1494501.

18. Faggiano F, Partanen T. Socioeconomic differences in cancer incidence and mortality. In: Kogevinas M, Pearce N, Susser M, Boffetta $P$, editors. Social inequalitites and cancer. Lyon: International Agency for Research on Cancer (IARC), 1997. IARC scientific publications, no 138

19. Cooper JA, Rohan TE, Cant ELMcK, Horsfall DJ, Tilley WD. Risk factors for breast cancer by oestrogen receptor status: a populationbased case-control study. Br J Cancer 1989;59:119-25.

20. Potter JD, Cerhan JR, Sellers TA, McGovern PG, Drinkard C, Kushi $L R$, et al. Progesterone and estrogen receptors and mammary neoplasia in the Iowa Women's Health Study: how many kinds of breast cancer are there? Cancer Epidemiol Biomarkers Prev 1995;4:319 26.

21. Krieger N. Exposure, susceptibility, and breast cancer risk: a hypothesis regarding exogenous carcinogens, breast tissue development, and social gradients, including black/white differences, in breast cancer incidence. Breast Cancer Res Treat 1989;13:205-23.

22. Ahlborg UG, Lipworth L, Titus-Emstoff L, Hsieh CC, Hanberg A, Baron $\mathrm{J}$, et al. Organochlorine compounds in relation to breast cancer, endometrial cancer, and endometriosis: an assessment of the biological and epidemiological evidence. Crit Rev Toxicol 1995;25:463531.

23. Wassermann M, Nogueira DP, Tomatis L, Mirta AP, Shibata H, Arie $G$, et al. Organochlorine compounds in neoplastic and adjacent apparently normal breast tissue. Bull Environ Contam Toxicol 1976:15:478-84.

24. Falck F Jr, Ricci A, Wolff MS, Godbold J, Deckers P. Pesticides and polychlorinated biphenyl residues in human breast lipids and their relation to breastcancer. Arch Environ Health 1992;47:143-6.

25. Unger M, Kiaer H, Blichert-Toft M, Olsen J, Clausen J. Organochlorine compounds in human breast fat from deceased with and without breast cancer and in a biopsy material from newly diagnosed patients undergoing breast surgery. Environ Res 1984;34:24-8. 
26. Mussalo-Rauhamaa H, Hasanen E, Pyysalo H, Antervo K, Kauppila R, Pantzar P. Occurrence of b-hexachlorocyclohexane in breast cancer patients. Cancer 1990;66:2124 8.

27. Wolff MS, Toniolo PG, LeeEW, Rivera M, Dubin L. Blood levels of organochlorine residues and risk of breast cancer. JNCI 1993;85:648-52.

28. Krieger N, Wolff MS, Hiatt RA, Rivera M, Vogelman J, Orentreich N. Breast cancer and serum organochlorines: a prospective study among white, black, and Asian women. JNCI 1994;86:589—99.

29. Van't Veer P, Lobbezoo IE, Martín-Moreno JM, Guallar E, GómezAracena J, Kardinaal AFM, et al. DDT (dicophane) and postmenopausal breast cancer in Europe: case-control study. BMJ 1997;315: 81-5.

30. Dewailly E, Dodin S, Verreault R, Ayotte P, Sauvé L, Morin J, et al. High organochlorine body burden in women with estrogen receptorpositive breast cancer. INCI 1994;86:232 - 4 .

31. Lopez-Carrillo L, Blair A, Lopez-Cervantes M, Cebrian M, Rueda C, Reyes $\mathrm{R}$, et al. Dichlorodiphenyltrichloroethane serum levels and breast cancer risk: a case-control study from Mexico. Cancer Res 1997;57:3728-32.

32. Kogevinas M, Becher H, Benn T, Bertazzi PA, Boffetta P, Bueno-deMesquita HB, et al. Cancer mortality in workers exposed to phenoxy herbicides, chlorophenols and dioxins: an expanded and updated international cohort study. Am J Epidemiol 1997;145:1061 -75.

33. Katz RM, Jowett D. Female laundry and dry cleaning workers in Wisconsin: a mortality analysis. Am J Public Health 1981;71:305-7.

34. Duh R, Asal NR. Mortality among laundry and dry cleaning workers in Oklahoma. Am J Public Health 1984;74:1278—80.

35. Blair A, Stewart PA, Tolbert PE, Grauman D, Moran FX, Vaught J, et al. Cancer and other causes of death among a cohort of dry cleaners. Br J Ind Med 1990;47:162-8.
36. Ruder AM, Ward EM, Brown DP. Cancer mortality in female and male dry-cleaning workers. J Occup Med 1994;36:867—74.

37. Anttila A, Pukkala E, Sallmen M, Hernberg S, Hemminki K. Cancer incidence among Finnish workers exposed to halogenated hydrocarbons. J Occup Environ Health 1995;37:797—806.

38. Labrèche FP, Goldberg MS. Exposure to organic solvents and breast cancer in women: a hypothesis. Am J Ind Med 1997;32:1-14.

39. Gammon MD, John EM. Recent etiologic hypotheses concerning breast cancer. Epidemiol Rev 1993;15:163-8.

40. Friedenreich CM, Rohan TE. A review of physical activity and breast cancer. Epidemiology 1995;6:311-7.

41. Rubin CH, Burnett CA, Halperin WE, Seligman PJ. Occupation as a risk identifier for breast cancer. Am J Public Health 1993;83: $1311-5$.

42. Pukkala E. Cancer risk by social class and occupation: a survey of 109,000 cancer cases among Finns of working age. Basel: Karger; 1995. Contributions to epidemiology and biostatistics, vol 7.

43. Morton WE. Major differences in breast cancer risks among occupations. J Occup Environ Med 1995;37:328-35.

44. Rix BA, Skov T, Lynge E. Socio-economic group, occupation and incidence of breast cancer and genital cancer among women in Denmark. Eur J Public Health. In press.

45. Pukkala E, Auvinen A, Wahlberg G. Incidence of cancer among Finnish airline cabin attendants. BMJ 1995;311:649-52.

46. Cantor KP, Stewart PA, Brinton LA, Dosemeci M. Occupational exposures and female breast cancer mortality in the United States. I Occup Environ Med 1995;37:336 - 48.

Received for publication: 18 November 1997 